\title{
Molecular genetic analysis of the yellow- breasted capuchin monkey: recommendations for ex situ conservation
}

\author{
C.G. Oliveira ${ }^{1}$, F.A. Gaiotto ${ }^{1}$, M.A. Costa ${ }^{2}$ and R.A. Martinez ${ }^{1}$ \\ ${ }^{1}$ Laboratório de Genética Molecular Aplicada, \\ Centro de Biotecnologia e Genética, \\ Universidade Estadual de Santa Cruz, Ilhéus, BA, Brasil \\ ${ }^{2}$ Laboratório de Citogenética, Centro de Biotecnologia e Genética, \\ Universidade Estadual de Santa Cruz, Ilhéus, BA, Brasil \\ Corresponding author: F.A. Gaiotto \\ E-mail: gaiotto@uesc.br
}

Genet. Mol. Res. 10 (3): 1471-1478 (2011)

Received October 20, 2010

Accepted December 15, 2010

Published July 25, 2011

DOI 10.4238/vol10-3gmr1115

\begin{abstract}
The yellow-breasted capuchin monkey, Cebus xanthosternos, is one of the most endangered species of the Brazilian Atlantic Forest. In situ conservation for this species is problematic due to habitat destruction; therefore, captive conservation has been considered as an alternative strategy. A Studbook for C. xanthosternos has been kept for more than 20 years; however, no genetic data has been collected. Our aim was to provide a preliminary assessment of the genetic variability of C. xanthosternos in captivity in Brazil and compare it with data from the wild. Microsatellite and mtDNA sequencing were carried out in 40 samples from five Brazilian institutions registered in the international Studbook and compared with 8 samples collected in a wild population from REBIO-Una/BA. DNA for analysis was extracted from hair, feces and blood. Our results showed that two of the five captive groups assessed had a genetic variability comparable to wild animals. However, the other three groups apparently require urgent management to improve its genetic
\end{abstract}


variability. Considering that inbreeding effects are more pronounced in captivity due to lack of gene flow, our data indicate a need to increase population size by introducing newly rescued individuals into these captive groups. Our results are the first attempt to provide genetic information for captive C. xanthosternos in Brazil.

Key words: Brazilian Atlantic forest; Cebus; Genetic diversity; Management programs

\section{INTRODUCTION}

The yellow-breasted capuchin monkey, Cebus xanthosternos Wied-Neuwied, 1826, is endemic to the Brazilian Atlantic forest. This species has been reported only in the south of Bahia State along the Paraguaçu River, near Salvador, as its northernmost limit, and the Jequitinhonha River as its southernmost limit. However, historically, this species had a distribution up to the São Francisco River as its northernmost and westernmost limits (Oliver and Santos, 1991; Coimbra-Filho et al., 1992; Rylands et al., 2005).

Some of its rapidly declining populations are within an area considered to be one of the most biodiverse points in the Atlantic Forest (Martini et al., 2007), which is prone to anthropic pressures, such as habitat loss and fragmentation due to deforestation. This scenario is worsened by hunting for subsistence or illegal commerce, which hinders recolonization of well-preserved forest fragments (Kierulff et al., 2005). As a consequence, this species was included in the IUCN Red List of Threatened Species, and an International Committee for Management and Conservation of C. xanthosternos and C. robustus was created in 1992. This committee is responsible for the Atlantic Forest capuchin in situ and ex situ conservation and captive management (Kierulff et al., 2005).

The C. xanthosternos Studbook had 160 registered individuals in 2007. Of these, 57 are housed in eight Brazilian institutions and the remainder in 17 European institutions. Molecular studies of such individuals can provide useful information for the establishment of management measures to avoid total loss of the original genetic diversity (Gilligan and Frankham, 2003).

We assessed the allelic and haplotypic variability of a fraction of the Brazilian Studbook members and of a wild population of C. xanthosternos. This initiative generated information for devising an appropriate strategy for the conservation of this species.

\section{MATERIAL AND METHODS}

Forty individuals, representing $70 \%$ of all animals kept in captivity in Brazil (registered in the Studbook up to it latest update), were sampled. Twelve individuals were housed at the Centro de Primatologia do Rio de Janeiro, RJ (CPRJ), eight individuals at Fundação Parque Zoológico de São Paulo, SP (SP), three individuals at the "Quinzinho de Barros" Zoo, in Sorocaba, SP (QB), six individuals at the Belo Horizonte Zoo, MG (BH), and 11 individuals at the Americana Zoo, SP (AM). DNA extractions were performed using both hair and feces samples. Feces and hair samples were also collected from eight individuals from a natural population at the Una Biological Reserve (REBIO-UNA, Bahia, Brazil). We extracted total DNA using a QIAmp DNA stool mini $\mathrm{kit}^{\mathbb{B}}$ and a QIAmp DNA mini kit ${ }^{\mathbb{B}}$ (Qiagen) according to 
manufacturer specifications for all samples.

Microsatellite primers designed for C. apella (Escobar-Paramo, 2000), for Saguinus mystax (Bohle and Zischler, 2002), for Saimiri boliviensis (Witte and Rogers, 1999), for Alouatta palliata (Ellsworth and Hoelzer, 1998), and for Homo sapiens verified as polymorphic for C. nigritus (Amaral et al., 2005) were tested for C. xanthosternos. We carried out polymerase chain reaction (PCR) amplifications of 36 microsatellite loci using the following cycling conditions: initial denaturation at $94^{\circ} \mathrm{C}$ for 4 min followed by 35 cycles of $94^{\circ} \mathrm{C}$ for $1 \mathrm{~min}$, variable annealing temperature for $50 \mathrm{~s}$, and $72^{\circ} \mathrm{C}$ for $1 \mathrm{~min}$, and an extension period of 10 min. All PCRs were performed in $20 \mu \mathrm{L}$ containing: $10 \mathrm{mM}$ Tris- $\mathrm{HCl}, \mathrm{pH} 8.3,50 \mathrm{mM}$ $\mathrm{KCl}, 0.25 \mathrm{mM} \mathrm{MgCl}, 0.5 \mathrm{mM}$ of each primer; $0.25 \mathrm{mM}$ of each dNTP; 300 ng DNA and 5 $\mathrm{U}$ Taq polymerase (Fermentas). One primer of each pair was labeled with an M13 primer tail according to Boutin-Ganache et al. (2001).

We used an ABI 377 automated sequencer for detection of PCR products using GeneScan and Genotyper 2.1 softwares (Applied Biosystems) for genotype determination.

We checked and corrected putative genotyping errors using MicroChecker 2.2.3 (Oosterhout et al. 2004). Values of gene diversity $\left(\mathrm{H}_{\mathrm{E}}\right)$, observed heterozygosity $\left(\mathrm{H}_{\mathrm{O}}\right)$, and genetic structure $\left(\mathrm{G}_{\mathrm{ST}}\right.$; Nei, 1978) were estimated using GENETIX 4.05 (Belkhir et al., 2004).

Amplification of a 680-bp fragment of the control region (D-loop) was performed using the primers CTACCATCAACACCCAAAG and CATCCAGTGACGCGGTTAAGA and PCR amplification conditions as described by Kocher et al. (1989).

Amplified PCR products were purified and sequenced using a MegaBace DNA Analysis System (Armersham Biosciences) with the DYEnamic ET Dye Terminator cycle sequencing kit (Armersham Biosciences). Sequences were aligned using Clustal W (Thompson et al., 1994), and the alignments were edited manually using Bioedit 7.0.0 (http://www.mbio.ncsu. edu/ BioEd- it/bioedit.html). The sequences obtained were deposited in GenBank.

Intraspecific historical lineages, population structuration and geographic distribution patterns were inferred using a haplotype network constructed by the medianjoining (MJ) network method (Bandelt et al., 1999) using NETWORK 4.5.0.0 (www. fluxus-engineering.com).

\section{RESULTS}

Of the 36 originally tested primers, only 12 resulted in positive amplifications and six were polymorphic for C. xanthosternos (PEPC8, PEPC59, SB19, D16S505, D4S411, and D2S382). Genotyping error analysis indicated no evidence of scoring error due to stuttering and no evidence of a large allele dropout; however, there was a homozygote excess at all loci, probably due to the presence of null alleles. Some studies have documented null alleles at microsatellite loci at frequencies of up to $15 \%$ (Callen et al., 1993).

Only two groups (CPRJ and SP) showed $\mathrm{H}_{\mathrm{E}}$ similar to that from the wild population (Table 1). $\mathrm{H}_{\mathrm{O}}$ for SP, Wild, and CPRJ populations (Table 1) were higher than those found in $\mathrm{QB}, \mathrm{AM}$, and $\mathrm{BH}$. The CPRJ group had the largest number of alleles per loci (Table 1). When $\mathrm{G}_{\text {ST }}$ pairwise comparisons were made, $\mathrm{SP}$ and CPRJ showed the lowest values (Table 2). QB and $\mathrm{BH}$ groups were found more recently, with individuals from different sources, probably mixing genetic pools. According to the Studbook information, AM and BH groups started with few individuals from the AM Zoo, with only one male and one female recognized as relatives. 
Table 1. Genetic diversity among captive and wild Cebus xanthosternos groups for multiple microsatellite alleles.

\begin{tabular}{lclllll}
\hline & CPRJ & SP & QB & AM & BH & Wild \\
\hline $\mathrm{A}$ & 10.0 & 5.8 & 3.6 & 4.0 & 0.453 & 2.6 \\
$\mathrm{H}_{\mathrm{E}}$ & 0.842 & 0.738 & 0.611 & 0.388 & 0.478 & 0.0 \\
$\mathrm{H}_{\mathrm{O}}$ & 0.656 & 0.705 & 0.333 & 0.143 & 0.467 & 0.023 \\
$\mathrm{f}$ & 0.220 & 0.044 & 0.455 & 0.110 \\
\hline
\end{tabular}

Mean number of alleles $(A)$, gene diversity $\left(\mathrm{H}_{\mathrm{E}}\right)$, observed heterozygosity $\left(\mathrm{H}_{\mathrm{O}}\right)$, and fixation index $(\mathrm{f})$. CPRJ = Centro de Primatologia do Rio de Janeiro; SP = Fundação Parque Zoológico de São Paulo; QB = "Quinzinho de Barros" Zoo; AM = Americana Zoo; BH = Belo Horizonte Zoo.

Table 2. Nei's (1978) $\mathrm{G}_{\mathrm{ST}}$ statistics comparing all captive and wild groups based on microsatellite data.

\begin{tabular}{lcccccc}
\hline Population & CPRJ & SP & BH & QB & AM & Wild \\
\hline CPRJ & - & 0.0797 & 0.1574 & 0.1345 & 0.1959 & 0.0905 \\
SP & & - & 0.1817 & 0.1703 & 0.2453 & 0.0890 \\
BH & & - & 0.2431 & 0.1587 & 0.1607 \\
QB & & & - & 0.2963 & 0.1685 \\
AM & & & & - & 0.2353 \\
Wild & & & & & - \\
\hline
\end{tabular}

For abbreviations, see legend to Table 1.

The lowest values of differentiation were attained in pairwise comparisons of Wild, CPRJ, and SP (Table 2). Moreover, the QB population had the highest $\mathrm{G}_{\mathrm{ST}}$ when compared with the $\mathrm{BH}$ and $\mathrm{AM}(0.2431$ and 0.2963 , respectively), probably a result of a founder effect associated with the establishment of captive populations. The SP and AM groups, although stemming from common ancestors, are quite different genetically. This could be due to genetic effects of inbreeding in the AM group, which strengthens the notion that it should be a management priority.

A total of 24 sequences of the mtDNA control region (Table 3 ) were confirmed using BLAST, and a consensus sequence of $455 \mathrm{bp}$ was obtained, aligning them with a sequence for C. albifrons (GenBank accession NC_002763.1). No indels were found.

Table 3. List of Cebus xanthosternos studied.

\begin{tabular}{lrll}
\hline & N & Studbook sample & Genbank accession No. \\
\hline Hapl_1 & 1 & $\# 113$ & 1397212 \\
Hapl_2 & 3 & $\# 68, \# 139$, Wild & $1397214,1397205,1397218$ \\
Hapl_3 & 2 & $\# 149, \# 153$ & 1397208,1397209 \\
Hapl_4 & 1 & $\# 84$ & 1397215 \\
Hapl_5 & 13 & $\# 26, \# 48, \# 98, \# 122, \# 185, \# 212, \# 82, \# 194, \# 4$, & $1397200,1397221,1397204,1397206,1397220,1397217$, \\
& & $\# 8, \# 69, \# 91$, Wild 1 & $1397211,1397213,1397216,1397210$ \\
Hapl_6 & 1 & $\# 51$ & 1397219 \\
Hap_7 & 1 & $\# 169$ & 1397203 \\
Hap_8 & 1 & \#210 & 1397191 \\
Hap_9 & 1 & Wild 2 & 1397201 \\
\hline
\end{tabular}

$\mathrm{N}$ is the number of specimens found for each haplotype. 
Base composition varied significantly among the different domains of the C.xanthosternos control region. It is similar to other mammals regarding a base composition of $\mathrm{T}>\mathrm{A}>\mathrm{C}>$ $\mathrm{G}$ and pattern of $(\mathrm{A}+\mathrm{T})>(\mathrm{C}+\mathrm{G})$ (Sbisá et al., 1997). The average nucleotide sequence composition was $56.8 \% \mathrm{~A}+\mathrm{T}, 43.1 \% \mathrm{G}+\mathrm{C}$. Among the animals analyzed, nine different haplotypes were identified (Templeton, 2001). Mean haplotype diversity was 0.7029 , and the estimated nucleotide diversity $(\pi)$ was 0.049 . As hypothesized, since the CPRJ group consisted of a large number of different wildlife origins, it was the most polymorphic, with 29 variable sites. Haplotype 5 was the most frequent: 13 individuals from four of five groups. This high frequency of only one haplotype was exclusive to captive populations, therefore representing additional evidence for the possible founder effect previously discussed. It is also interesting to highlight that haplotype 9 was exclusive to the wild population. The MJ network showed a close-knit relationship among all haplotypes, with one mutational step and at the most one median vector separating the two most common haplotypes. We detected that there is more than one mutational path between almost all haplotypes. The fact that there are haplotypes exclusive to the wild population also supports a separation broader than could be expected between wild samples and captive ones, since the wild population is only around 30 years old. Haplotypes found only in captive individuals cannot be considered exclusive to the captive population until more wild animals are sampled.

The AM group was the most divergent, with three exclusive haplotypes $(4,6$, and 7$)$ from a total of four, consistent with levels of genetic divergence revealed by microsatellite analysis (Table 2). CPRJ and BH showed two (1 and 4) and one (8) exclusive haplotypes, respectively. CPRJ showed the greatest estimated haplotypic distance (Figure 1) and the highest haplotypic diversity, 0.716 .

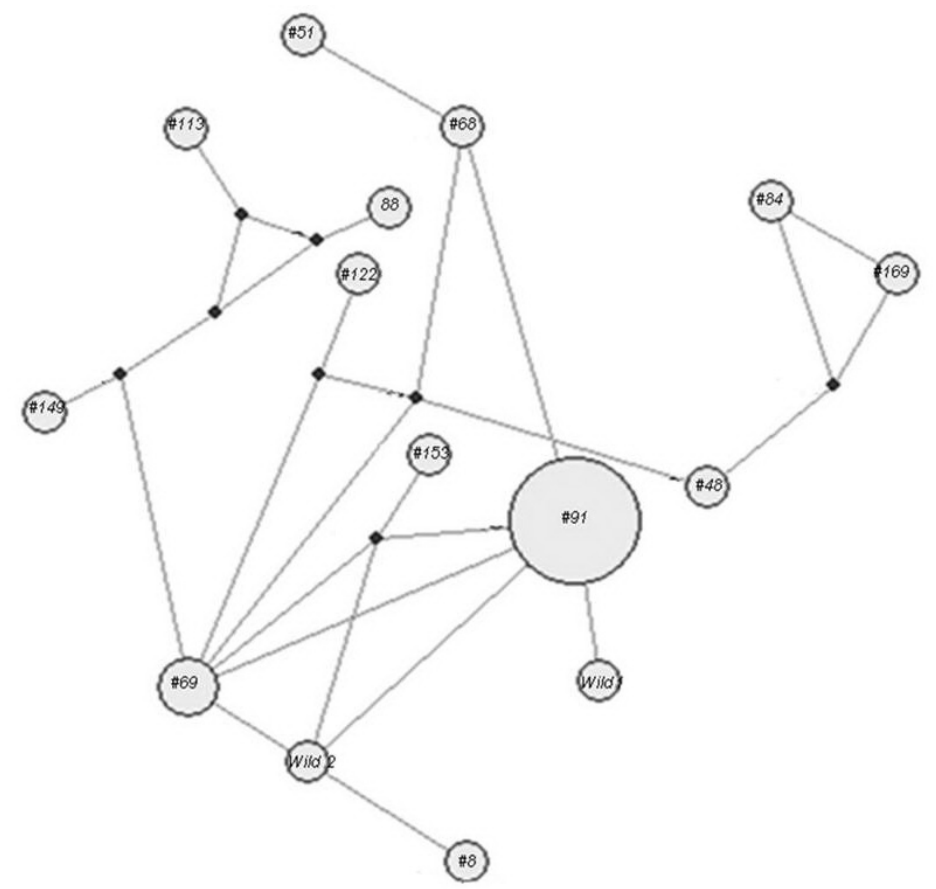

Figure 1. Median joining haplotype network for all samples. Darker points represent median joining vectors. Size of circles is proportional to the number of specimens sharing each haplotype. 


\section{DISCUSSION}

The maintenance of captive populations through an ex situ conservation program is useful to avoid species extinction, especially in seriously threatened biomes, as in the case of the Atlantic Forest in Brazil. However, this initiative tends to be inefficient if not associated with in situ conservation strategies. In spite of the captive yellow-breasted capuchin monkey population being at least 20 years old, and according to Studbook's first records, this study showed the first genetic variability estimates for the species. Based on our analyses, it was possible to diagnose genetic aspects of the Brazilian captive population and compare them to wildlife parameters. Our results help in proposing management recommendations for captive populations, in order to minimize genetic drift and inbreeding depression. Similar studies were conducted for other endangered species, such as the Iberian wolf (Ramirez et al., 2006) and the Jamaican yellow boa (Tzika et al., 2009).

According to Studbook records, the CPRJ population is the oldest captive group, founded with animals from different locations, ranging from the northern to the southern extremes of the species' distribution. Original founders were brought from the wild in 1980 and their offspring were transferred to Brazilian (BH, QB, SP, and AM) and European zoos. $\mathrm{H}_{\mathrm{E}}$ for CPRJ and SP is similar to that found for the wild population, reflecting the wild origin of its founders. Our genetic results showed that the CPRJ group is the most important among the Brazilian captive populations, since it preserves the largest genetic variability, including the number of alleles, gene diversity, and haplotypic diversity. The genetic parameters estimated are also in accordance with the historic information from the Studbook (e.g., the CPRJ group received the greatest number of unrelated founders).

The higher genetic diversity found in SP and CPRJ groups when compared with $\mathrm{BH}$ and QB should be considered for management purposes, such as the exchange of individuals between institutions. Comparisons of results were limited since there is no previous study of genetic variability for C. xanthosternos and because few reports for other Cebus species in captivity have been published. Amaral et al. (2005) analyzed two Cebus nigritus semi-captive groups, in a forest fragment in a semi-urban zone of Ribeirão Preto, SP, Brazil. They obtained a similar mean $\mathrm{H}_{\mathrm{E}}$ of 0.711 using three polymorphic microsatellite loci compared with our 0.73 for the $\mathrm{BH}$ and SP groups using five microsatellite loci. As BH and SP belong to the same gene pool and since there has been exchange of individuals between them over the years, it is possible to make comparisons with the genetic variability found for this semi-captive group of $C$. nigritus.

Rudnick and Lacy (2008) used computer simulations to investigate the retention of genetic diversity and inbreeding in captive populations, changing the number of founders (10, 30 , and 100 individuals) and assuming that founders are unrelated and not inbred. Results indicated that $0-2 \%$ more genetic diversity over 10 generations was retained when 100 unrelated founders were considered. Similarly, $0-2 \%$ less inbreeding was detected in the same conditions. Therefore, to retain a population genetic variability with a low rate of inbreeding, it is mandatory that all C. xanthosternos captive populations analyzed have a larger effective number of unrelated founders.

Our results showed extremely low values of genetic variability as a warning signal of a high potential for inbreeding depression. We recommend that Brazilian groups should be priorities in the Committee's management plans, including the strategic trading of individuals from one zoo to another, as to increase their genetic diversity. 
The low estimated haplotypic diversity for $\mathrm{QB}$ and $\mathrm{BH}$ also indicates that these populations should be a priority for future management procedures. Therefore, our genetic results could be useful in guiding matings in order to optimize parental contributions to the genetic diversity of captive populations following the methodology of Caballero et al. (2010), which makes management more efficient. Furthermore, the introduction of newly rescued individuals into these captive populations could also help minimize inbreeding depression.

\section{CONCLUSIONS}

In summary, our results provide guidance for efficient ex situ management programs for $C$. xanthosternos in the future. We suggest an increase in the number of individuals in all captive populations with specimens rescued by government agencies. Planned intercrosses between individuals from the $\mathrm{BH}, \mathrm{AM}$, and QB populations with those from the SP and CPRJ populations should be performed, since the latter have a genetic diversity more similar to the wild population. These measures should be priorities aimed at preventing further loss of the population's fitness and evolutionary potential due to loss of genetic variability, as is currently the case.

\section{ACKNOWLEDGMENTS}

We thank María Cecília Martins Kierulff and collaborators, Gustavo Rodrigues Canale, Lilian Silva Catenacci, Cibele Bonvicino, and Alcides Pissinatti and his staff for helping with logistics and sample collection. Samples were collected under permission from IBAMA (\#13816-1). Research supported by the Critical Ecosystem Partnership Fund (CEPF) and the Margot Marsh Foundation (MMF). NGOs Mulleriana and IESB are our partners in this and other research regarding several aspects of yellow-breasted capuchin monkey's genetics and management. Jean Marc Lernould and Christian Roos provided valuable insight. We also thank the Brazilian National Research Council - CNPq for awarding a research fellowship to F.A. Gaiotto and M.A. Costa, and FAPESB for PhD fellowships to C.G. Oliveira. This manuscript was greatly improved with helpful comments from D. Garcia, R.X. Corrêa, and J.G.S. Miller.

\section{REFERENCES}

Amaral JM, Simoes AL and De Jong D (2005). Allele frequencies and genetic diversity in two groups of wild tufted capuchin monkeys (Cebus apella nigritus) living in an urban forest fragment. Genet. Mol. Res. 4: 832-838.

Bandelt HJ, Forster P and Rohl A (1999). Median-joining networks for inferring intraspecific phylogenies. Mol. Biol. Evol. 16: 37-48.

Belkhir K, Borsa P, Chikhi L and Raufaste N (2004). GENETIX 4.05, Logiciel sous Windows TM pour la Genetique des Populations. Laboratoire Génome, Populations, Interactions, CNRS UMR 5171, Université de Montpellier II, Montpellier.

Bohle UR and Zischler H (2002). Polymorphic microsatellite loci for the moustached tamarin (Saguinus mystax) and their cross-species amplification in the New World monkeys. Mol. Ecol. Notes 2: 1-3.

Boutin-Ganache I, Raposo M, Raymond M and Deschepper CF (2001). M13-tailed primers improve the readability and usability of microsatellite analyses performed with two different allele-sizing methods. Biotechniques 31: 24-6, 28.

Caballero A, Rodríguez-Ramilo ST, Ávila V and Fernández J (2010). Management of genetic diversity of subdivided populations in conservation programmes. Conserv. Genet. 11: 409-419.

Callen DF, Thompson AD, Shen Y, Phillips HA, et al. (1993). Incidence and origin of "null" alleles in the (AC)n microsatellite markers. Am. J. Hum. Genet. 52: 922-927. 
Coimbra-Filho AF, Rylands AB, Pissinatti A and Santos IB (1992). The distribution and status of the buff-headed capuchin monkey, Cebus xanthosternos Wied 1820, in the Atlantic Forest region of eastern Brazil. Prim. Conserv. 12/13: 24-30.

Ellsworth JA and Hoelzer GA (1998). Characterization of microsatellite loci in a New World primate, the mantled howler monkey (Alouatta palliata). Mol. Ecol. 7: 657-658.

Escobar-Paramo P (2000). Microsatellite primers for the wild brown capuchin monkey Cebus apella. Mol. Ecol. 9: 107108.

Gilligan DM and Frankham R (2003). Dynamics of genetic adaptation to captivity. Conserv. Genet. 4: 189-197.

Kierulff MCM, Santos GR, Canale GR and Guidorizzi CE (2005). Plano de Manejo para a Conservação do Macaco-Pregodo-Peito-Amarelo, Cebus xanthosternos. Relatório apresentado ao PROBIO-MMA.

Kocher TD, Thomas WK, Meyer A, Edwards SV, et al. (1989). Dynamics of mitochondrial DNA evolution in animals: amplification and sequencing with conserved primers. Proc. Natl. Acad. Sci. U. S. A. 86: 6196-6200.

Martini AMZ, Fiaschi P, Amorim AM and Paixão JL (2007). A hot-point within a hot-spot: a high diversity site in Brazil's Atlantic Forest. Biodiv. Cons. 16: 3111-3128.

Nei M (1978). Estimation of average heterozygosity and genetic distance from a small number of individuals. Genetics 89: 583-590.

Oliver WLR and Santos IB (1991). Threatened endemic mammals of the atlantic forest region of South-East Brazil. $J$. Wildl. Preserv. Trust 4: 1-126.

Oosterhout CV, Hutchinson WF, Wills DPM and Shipley P (2004). MICRO-CHECKER: software for identifying and correcting genotyping errors in microsatellite data. Mol. Ecol. Notes 4: 535-538.

Ramirez O, Laura A, Enseñat C, Vilà C, et al. (2006). Genetic assessment of the Iberian wolf Canis lupus signatus captive breeding program. Conserv. Genet. 7: 861-878.

Rudnick JA and Lacy RC (2008). The impact of assumptions about founder relationships on the effectiveness of captive breeding strategies. Conserv. Genet. 9: 1439-1450.

Rylands AB, Kierulff MCM and Mittermeier RA (2005). Notes on the taxonomy and distributions of the tufted capuchin monkeys (Cebus, Cebidae) of South America. Lundiana 6: 97-110.

Sbisá E, Tanzariello F, Reyes F, Pesole G, et al. (1997). Mammalian mitochondrial D-loop region structural analysis: identification of new conserved sequences and the functional and evolutionary implications. Gene 205: 125-140.

Templeton AR (2001). Using phylogeographic analyses of gene trees to test species status and processes. Mol. Ecol. 10: 779-791.

Thompson JD, Higgins DG and Gibson TJ (1994). CLUSTAL W: improving the sensitivity of progressive multiple sequence alignment through sequence weighting, position-specific gap penalties and weight matrix choice. Nucleic Acids Res. 22: 4673-4680.

Tzika AC, Remy C, Gibson R and Milinkovitch MC (2009). Molecular genetic analysis of a captive-breeding program: the vulnerable endemic Jamaican yellow boa. Conserv. Genet. 10: 69-77.

Witte SM and Rogers J (1999). Microsatellite polymorphisms in Bolivian squirrel monkeys (Saimiri boliviensis). Am. J. Primatol. 47: 75-84. 